\title{
periferio
}

\section{"PARA AMPARAR OS MENINOS DESVALIDOS DA SOCIEDADE": INSTITUCIONALIZAÇÃO E FINANCIAMENTO DO PATRONATO SÃO BENTO (1955-1959)}

\author{
Marcia Spadetti Tuão da Costa ${ }^{1}$ \\ Centro de Pesquisa, Memória e História da Educação da \\ Cidade de Duque de Caxias e Baixada Fluminense
}

\section{Resumo}

Apresentamos resultados de pesquisa em andamento sobre o Patronato São Bento (1959) em Duque de Caxias. Através da análise do acervo do Patronato, identificamos a institucionalização, o financiamento e sua função social a partir da bibliografia sobre patronato e ruralismo. Investigamos as relações estabelecidas entre o poder público e o Patronato, as verbas para as ações educativas, o projeto assistencial para essa infância no município entre 1955 e 1959. Estabelecemos diálogo com os estudos de Bonato (2005), de Gramsci (2007), de Mendonça (2007), de Câmara (2010) e de Dias (2014) para pensar a história local, o campo da história da infância e a configuração do financiamento como mobilizador das correlações de força entre distintos agentes da sociedade política e civil.

Palavras-chave: infância empobrecida; patronato; financiamento; Duque de Caxias

\footnotetext{
${ }^{1}$ Diretora Executiva do Centro de Pesquisa, Memória e História da Educação da Cidade de Duque de Caxias e Baixada Fluminense e Mestranda Programa de Pós-graduação em Educação, Cultura e Comunicação em Periferias Urbanas (PPGECC) da Faculdade de Educação da Baixada Fluminense (UERJ - Duque de Caxias). Rio de Janeiro, Brasil.
} 


\section{periferio}

\section{"SUPPORTING HELPLESS BOYS FROM SOCIETY": INSTITUTIONALIZATION AND FINANCING FROM \\ PATRONATO SÃO BENTO (1955-1959)}

\section{Abstract}

The results of the ongoing research about Patronato São Bento (1959) were presented in Duque de Caxias. Through the analysis of the Patronato's collection, we identified the institutionalization, the financing and their social function from the bibliography about patronato and rurality. We investigated the established relationships between the public power and Patronato, the funds for the educational actions, the care project for this childhood in the county between 1955 and 1959. It was established a dialog with Bonato (2005), Gramsci (2007), Mendonça (2007), Câmara (2010) and Dias' studies (2014) to think the local history, the childhood history field and the configuration of the financing as a mobilizing of the force correlations between different agents from political and civil society.

Keywords: impoverished childhood; patronato; financing; Duque de Caxias 


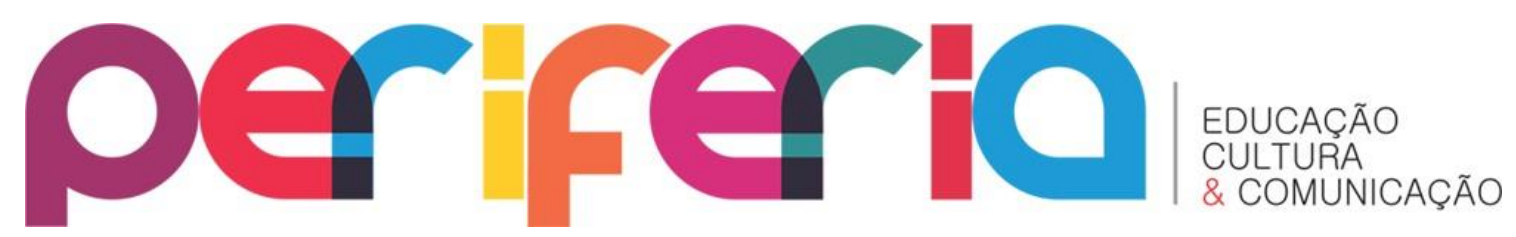

\section{INTRODUÇÃO}

O presente estudo reforça a importância do cuidado com os arquivos institucionais como fonte de informação das políticas públicas para os meninos. Cabe ressaltar e registrar que o investimento em políticas públicas na constituição do arquivo público municipal é nossa preocupação como elo essencial para a compreensão da história da educação da cidade de Duque de Caxias. Já que atualmente, desempenho esse duplo e árduo papel de organizadora e pesquisadora do referido acervo. As atividades desenvolvidas pelo projeto do Centro de Pesquisa, Memória e História da Educação da Cidade de Duque de Caxias e Baixada Fluminense (CEPEMHEd) ${ }^{2}$ em busca de informações sobre o processo de escolarização do município de Duque de Caxias, levou a identificação do acervo da Associação Beneficente de Menores (ABM) com milhares de documentos que apontam para o surgimento do Patronato São Bento, em 1959, segundo Relatório das atividades da ABM do ano de $1959^{3}$.

O Patronato São Bento foi uma instituição criada pela Associação Beneficente de Menores (ABM), em Duque de Caxias, fundada pela Mitra Diocesana de Petrópolis em 25 de novembro de $1955^{4}$ e era composta pela sociedade civil, com cunho filantrópico e vinculada a Igreja Católica

\footnotetext{
20 projeto de criação do CEPEMHEd, Decreto $n^{\circ} 4805$, de 2005, consolida uma das conquistas dos educadores da rede pública deste município, constituindo-se como direito à memória e à história da educação. A instituição surge da reivindicação dos profissionais da educação da rede municipal de Duque de Caxias e se propõe a oportunizar um espaço de fomento à produção e divulgação de pesquisas; de formação docente; de arquivamento e tratamento de dados coletados sobre a história e as memórias da educação do município de Duque de Caxias e da Baixada Fluminense e, igualmente, de Educação Patrimonial. 0 prédio da sede do CEPEMHEd, situado na rua Benjamin da Rocha Júnior, $\mathrm{s} / \mathrm{n}^{\circ}$, faz parte do conjunto de edificações do Museu Vivo do São Bento, primeiro ecomuseu da Baixada Fluminense, localizado no bairro São Bento, $2^{\circ}$ distrito, de Duque de Caxias. Instituição em que atuo como diretora executiva.

${ }^{3}$ CEPEMHEd, Acervo Patronato São Bento, Relatório das atividades de 1959, PSB 095.1, caixa 003. Daqui em diante registrarei os documentos referentes a esse acervo apenas pelo número do documento e da caixa.

${ }^{4}$ Ata de Assembleia da atual ASPAS (Ação Social Paulo VI), de $1^{\circ}$ de março de 1978, PSB 340.1, caixa 004.
} 


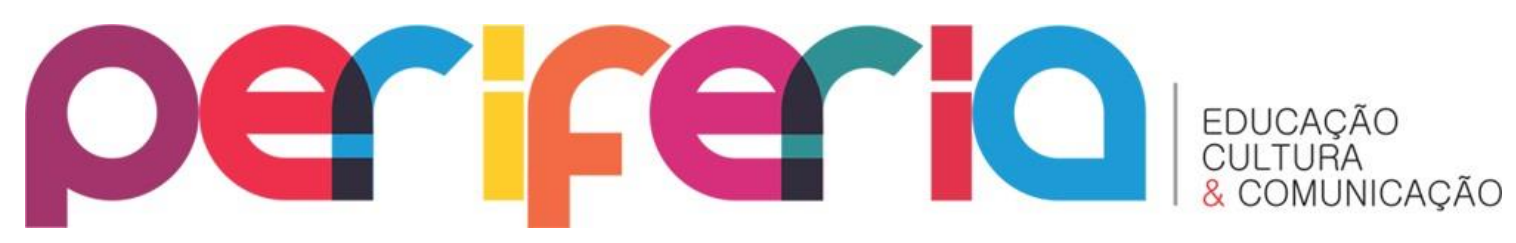

Apostólica Romana. Para que sua finalidade fosse alcançada, criou um patronato que ao longo dos anos foi modificando a sua forma de atuação e de intervenção com alterações no projeto institucional em todas as áreas, devido à alteração da atuação da Igreja, das políticas públicas e do poder local da região, como consequência do projeto de país para a infância e a juventude empobrecida. Foi, também, um espaço de internamento onde caberia à autoridade diocesana indicar o diretor, como organizar a administração e consequentemente, os menores deveriam ser educados de acordo com os princípios da igreja 5 .

A instituição do Patronato recebeu ao longo de sua atuação verbas de diferentes setores para sua manutenção. 0 projeto ruralista que perpassou a mesma, como as agências e os agentes envolvidos nessa instituição na cidade de Duque de Caxias e a compreensão de como funcionou financeiramente, é o objetivo central deste artigo. Isso significa investigar a $A B M$ e sua institucionalização para compreendermos a do Patronato, assim como suas relações internas e externas. Ou seja, identificar os acordos firmados entre o público e o privado para entendermos os usos do dinheiro. Assim como, entender como aconteceu a internação dessa infância específica nesse espaço, suas imbricações com a atuação da Igreja Católica, do poder público municipal e da implementação de políticas públicas sobre essa determinada infância no Brasil, a partir de uma análise mais restrita sobre o município de Duque de Caxias. Para isso, trabalhamos com os relatórios, os ofícios dos anos iniciais e o livro-caixa (1956 a 1963), o último assinado pelo o presidente da ABM e o prefeito da cidade de 1956 a 1959.

Nesse caminho, estabelecemos um diálogo com autores como Antonio Gramsci (1981; 2002; 2007), para trabalhar com o conceito de Estado ampliado no sentido de mapear as instituições e as agremiações que constituíram o processo histórico da infância em situação de pobreza no município, compreendendo-as como lugar de tensão e conflito. Identificando,

\footnotetext{
${ }^{5}$ Estatuto da ABM de 1956, PSB 076.6, caixa 003.
} 


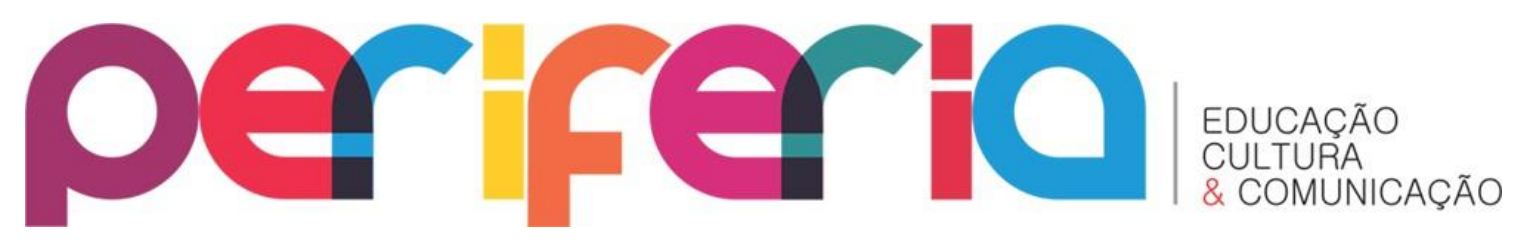

assim, nas práticas educacionais e nos projetos defendidos pelos diferentes agentes e agências, o que querem, quem são e onde estão.

\section{DE PATRONATO AGRÍCOLA A PATRONATO DE MENORES}

Os Patronatos Agrícolas surgiram a partir da Abolição da Escravatura, em 1888, para atender, inicialmente, a demanda de mão-de-obra no setor agrícola e de certa maneira, a propalada “crise” instalada nesse período.

$\mathrm{Na}$ reorganização das classes produtoras nesse período, destacaram-se duas entidades, uma formada no eixo São Paulo - SPA (Sociedade Paulista de Agricultura), outra, no eixo Nordeste, Sudeste e Sul - SNA (Sociedade Nacional de Agricultura). Ambas foram criadas no final do século XIX e enfrentavam dificuldades concretas no mercado internacional, além de apresentarem posicionamentos diferenciados para sua superação.

A SPA apostava no trabalho agrícola com os imigrantes, enquanto a SNA, no "trabalhador nacional6" com formação educacional, além de uma atuação do Estado. A primeira representava o poder hegemônico do Estado enquanto a segunda, "um eixo alternativo de poder na Primeira República" (MENDONÇA, 2010).

A SPA apostava no trabalho agrícola com os imigrantes, enquanto a SNA, no "trabalhador nacional" com formação educacional, além de uma atuação do Estado. A primeira representava o poder hegemônico do Estado enquanto a segunda, "um eixo alternativo de poder na Primeira República" (MENDONÇA, 2010).

A necessidade de usar o "trabalhador nacional" pelos ruralistas fluminenses, devido à falta de recursos para importação de imigrantes,

\footnotetext{
${ }^{6}$ Sua principal característica seria a reatualização de formas de trabalho compulsório no imediato pós abolição, assegurada por uma indissolúvel, ainda que contraditória, aliança entre proprietários agrários e Estado (MENDONÇA, 2010).

7 Sua principal característica seria a reatualização de formas de trabalho compulsório no imediato pós abolição, assegurada por uma indissolúvel, ainda que contraditória, aliança entre proprietários agrários e Estado (MENDONÇA, 2010).
} 


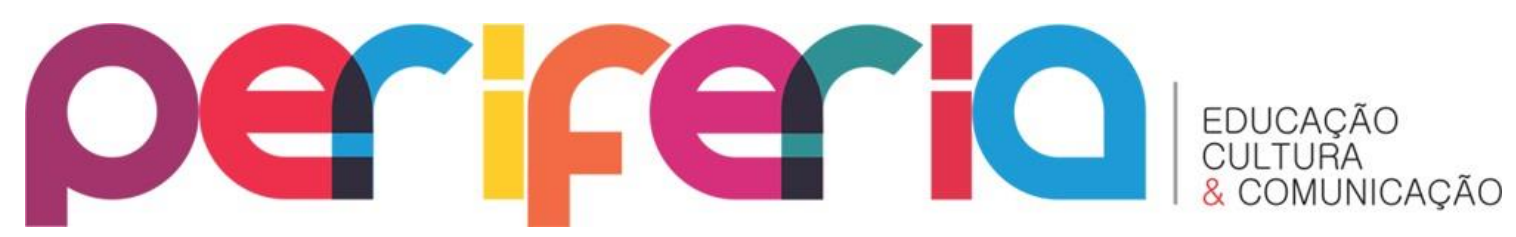

implicou na construção de um discurso da necessidade de "educar esse trabalhador" para superação da crise agrícola, capacitando-o em novos métodos de trabalho com uma mentalidade de valorização do trabalho agrícola e de fixação no campo.

A fixação desse trabalhador estava vinculada ao projeto educacional do período no solo fluminense. Através da educação e da viabilização do escoamento da produção agrícola para o então, distrito federal (consumo interno e exportação), foi sendo delineado o fazer educacional pelo viés ruralista. Houve a disseminação da ideia de que a superação da "crise" seria possível pela “modernização” do país agrário, principalmente, na região fluminense. Mas, não uma “modernização" que se opusesse ao agrário, mas uma "modernização" que estaria vinculada a inclusão de técnicas e equipamentos no trato da terra e dos animais, logo, a apreensão desse saber estaria vinculado à educação e ao combate do analfabetismo.

A estratégia oficial utilizada para fixar esse trabalhador nacional foi através do MAIC - Ministério da Agricultura, Indústria e Comércio com a criação de Aprendizados Agrícolas (AAs) e posteriormente, Patronatos Agrícolas (PAs). Nas fazendas, eram estabelecidos os AAs, onde a formação educacional tinha uma duração de dois anos, o público-alvo eram os filhos dos pequenos agricultores, num sistema de internato (MENDONÇA, 2007).

Esses AAs forneciam todo ambiente necessário para o aprendizado referente ao trato da terra e demais habilidades no que dizia respeito à criação de animais. Cada interno tinha uma diária atribuída a ele, que conforme tivesse retorno econômico do que seria produzido pelo educando, o administrador do mesmo direcionava a renda obtida para o pagamento dessa diária, que a princípio seria subsidiada pelo MAIC. Isso significava que essa instituição subsistiria financeiramente com 0 que produzisse. Eram verdadeiros "viveiros de mão-de-obra", onde os fazendeiros da vizinhança recrutavam, sistemática e gratuitamente, contingentes para o trabalho sazonal em suas terras (MENDONÇA, 2007). 


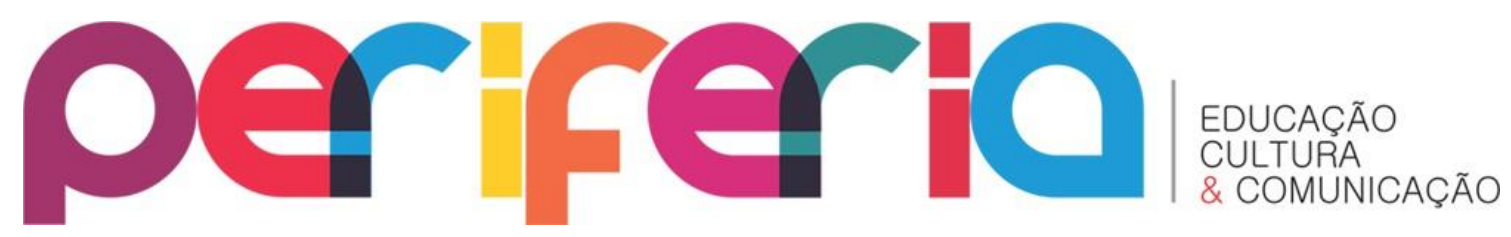

Em 1918, com o crescimento populacional das cidades, o MAIC criou os PAs com uma atuação paliativa para a questão social urbana. Sônia Regina de Mendonça (2007) apresenta essa questão quando fala sobre o grupo assistido que "recrutados pelos Chefes de Polícia e Juízes da cidade do Rio de Janeiro, a Capital Federal - autoproclamados como 'guardiões' da ordem social. Estabelecia-se, assim, uma triangulação entre o Ministério da Agricultura, Poder Judiciário e a Polícia do Distrito Federal". A autora ainda explica o que seriam os "guardiões" da ordem social:

\begin{abstract}
A presença da Polícia do Rio de Janeiro junto aos Patronatos não se limitava, apenas à arregimentação dos menores, inserindo-se junto à produção de um perfil disciplinar e de certa identidade institucional, já que boa parte da clientela provinha, antes de seu encaminhamento aos PAs, de duas instituições: ora o Depósito de Presos, ora a Colônia Correcional, ambas na Capital Federal e subordinadas ao Chefe de Polícia (MENDONÇA, 2010).
\end{abstract}

Com esse novo perfil e diante da realidade da urbanização, baseada nos Relatórios do Ministério da Agricultura, Indústria e Comércio (RMAIC), Mendonça afirma que entre 1918 e 1930, o total dos PAs saltou de 05 para 98. Isso porque essas instituições passaram a representar uma mediação: "entre 'mundo rural' e 'mundo urbano', avalizando a 'paz social' entre eles. Contribuindo para a construção de um paradigma de urbanização 'moderna' e 'profilática', o Ministério acabava por respaldá-lo [...]” (MENDONÇA, 2007).

Percebemos, assim, como o MAIC interferiu de maneira incisiva na educação do país permanecendo através do tempo, apesar da criação do Ministério da Educação e Saúde em 1930. As atuações se modificaram no transcorrer do tempo, mas a intervenção na educação persistiu, num viés de educação profissionalizante, instituindo o trabalho agrícola como uma solução para a questão social, ao mesmo tempo em que no momento da Era Vargas, o controle social era o imperativo.

0 projeto posto em prática no período correspondia à fixação do homem na sua região através da identificação com o espaço rural fluminense 


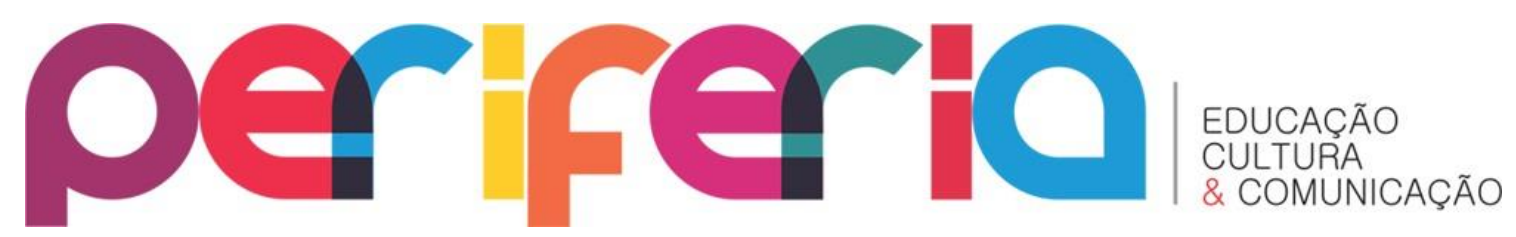

aliada a ideia de progresso através da implementação de escolas por meio de convênios municipais, ou seja, um projeto ruralista vinculado à educação. Educação essa que era oferecida aos meninos internos do patronato, assim como aos moradores do Núcleo Colonial através da escola. A partir da perspectiva do estudo da história local da Baixada Fluminense e da historiografia educacional fluminense, buscamos também refletir sobre as relações entre o território e os projetos de nação, sociedade e Estado. A experiência do Patronato São Bento permite perceber como as noções sobre rural e urbano incidiam sobre as funções sociais da escolarização e os destinos almejados para os menores. Criado em território confinado a uma política ruralista, nos anos 1930, a instituição que emerge nos anos 1950 é perpassada e significada, também, pelas transformações urbanas e fundiárias em curso na cidade de Duque de Caxias, assim como pela relação dessa região periférica com a capital federal e com a peculiaridade de ser destinada ao recolhimento de "menores".

\section{PATRONATO SÃO BENTO: UMA INSTITUIÇÃO ESCOLAR DENTRO DO NÚCLEO}

O Patronato São Bento, localizou-se na antiga Fazenda São Bento, comprada pelos Beneditinos em 1591. Lembramos, ainda, que esse mesmo espaço foi marcado pela Fazenda do Aguassu, pertenceu à sesmaria de Cristóvão Monteiro que a recebera da Coroa Portuguesa, por ocasião do fim da guerra contra os franceses.

Após a morte de Monteiro em 1596, a viúva daquele fidalgo português doou outra porção de terras ao mesmo Mosteiro. Iniciava-se assim, a colonização do Vale do Rio Iguaçu, a fazenda funcionou por um grande período nesse espaço. Até que em 1921, o terreno foi desapropriado para sediar a colônia agrícola. Em 1922, a Empresa de Melhoramentos da Baixada Fluminense desapropriou a Fazenda São Bento do Iguaçu, saneando-a e fazendo benfeitorias. 


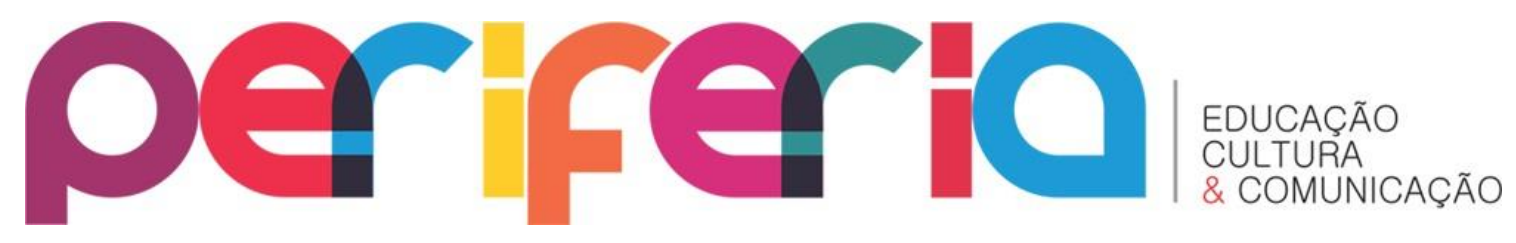

Em 1931, o contrato da Empresa foi rescindido e seus bens (entre eles, a Fazenda de São Bento) foram repassados para o Governo Federal. Em 1932, através do Decreto 22.226, o governo criou o Núcleo Colonial São Bento8, encarregado por lotear a Fazenda, colonizar, desobstruir o Rio de Janeiro e garantir o seu abastecimento alimentar: "Cria-se o Núcleo Colonial 'São Bento', em terras da Fazenda Nacional do mesmo nome, no município de Nova Iguassú, Estado do Rio de Janeiro"'.

Dessa forma, o Núcleo Colonial São Bento estava subordinado ao Ministério da Agricultura e se vinculava aos projetos políticos e econômicos, vigentes no estado do Rio de Janeiro e na Baixada Fluminense, para os usos do território e de sua gente (DIAS, 2014). Esse Núcleo tinha um administrador e uma guarita na entrada, funcionando como um condomínio fechado. Para um visitante, entrar naquele espaço, sua presença era anunciada e permitida se algum morador do local o estivesse aguardando.

Nesse período, não havia ônibus que circulasse por dentro do Núcleo, existia apenas um caminhão que fazia o transporte para os locais previamente estabelecidos pelo administrador. Além disso, o colono recebia lotes rurais, com garantia de que o escoamento da produção teria destino certo. Para conseguir um lote, havia a necessidade de uma inscrição no Ministério da Agricultura. No início, o colono não pagava pelo lote, além de ter custeado as ferramentas para o plantio, as mudas e os serviços médicos. Após três anos, começava-se contar dez anos para quitar a dívida referente ao terreno.

É nesse território que foi estabelecida uma instituição para cuidar desses meninos considerados carentes ou infratores. Os aspectos instituintes da mesma trazem a reflexão sobre que características a determinam ou não, como escolar. Para isso, dialogamos com outros autores para compreendermos esse processo.

\footnotetext{
8 Neste período, a cidade de Duque de Caxias ainda era um distrito de Iguaçu, sendo emancipada em 31 de dezembro de 1943.

9 As informações sobre esse decreto estão disponíveis em: http://www.lexml.gov.br/urn/urn:lex:br:federal:decreto:1932-12-14;22226. Acesso em mai, 2016.
} 


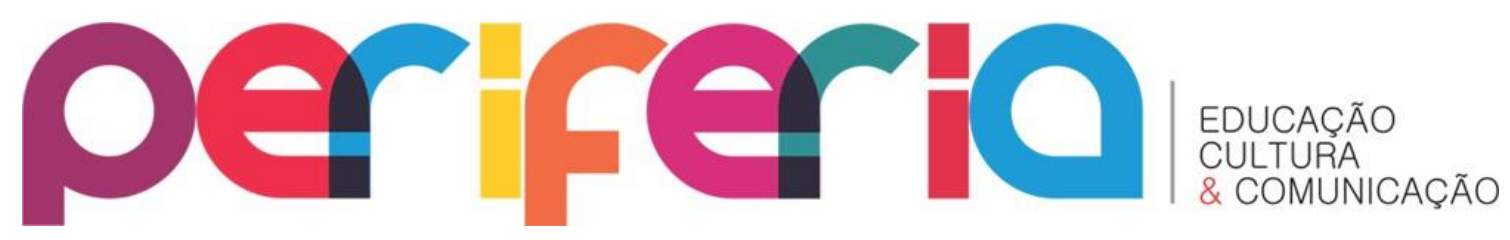

Desse modo, Saviani (2007) caracteriza as instituições com um caráter social, já que são criadas pelos seres humanos em resposta a uma necessidade. Mas, apesar de responder a essa necessidade, não são transitórias. Pelo contrário, permanecem como um sistema de práticas com seus agentes através da operação de instrumentos para determinado fim. Pelas características descritas anteriormente, as instituições são unidades de ação. Ele ainda afirma que as mesmas surgem a partir de atividades que eram realizadas anteriormente informalmente, assistematicamente e que num determinado momento, houve necessidade de que fossem institucionalizadas. Logo, uma atividade secundária que se originou de uma atividade primária, ou seja, espontânea. As instituições, ainda, tem a necessidade de autorreprodução, o que confere determinada autonomia. Segundo o mesmo autor, essas características se referem às instituições educativas também.

Ao analisarmos as sociedades humanas, percebemos que as instituições educativas são produtos desta informalidade, assistemática, enfim, original da educação. Mas, não podemos desconsiderar o fato de que as atividades educativas não estão relacionadas apenas às instituições educativas e sim, relacionadas a outras instituições que também desempenharam um caráter educativo, como afirma Saviani:

Assim, para além da instituição familiar consagrada, pelas suas próprias características, ao exercício da educação espontânea, vale dizer, do trabalho pedagógico primário, encontramos instituições como sindicatos, igrejas, partidos, associações de diferentes tipos, leigas e confessionais, que, além de desenvolver atividade educativa informal, podem, também, desenvolver trabalho pedagógico secundário, seja organizando e promovendo modalidades específicas de educação formal, seja mantendo escolas em caráter permanente. E não podemos perder de vista que a própria família, embora se dedicando precipuamente ao trabalho pedagógico primário, portanto, não institucionalizado, albergou durante um período de tempo relativamente longo a instituição do preceptorado realizando, pois, trabalho pedagógico secundário. Contudo, em matéria de oferta de educação formal, as instituições que se destacam nitidamente entre as demais são, sem dúvida, a Igreja e o Estado. (SAVIANI, 2007) 


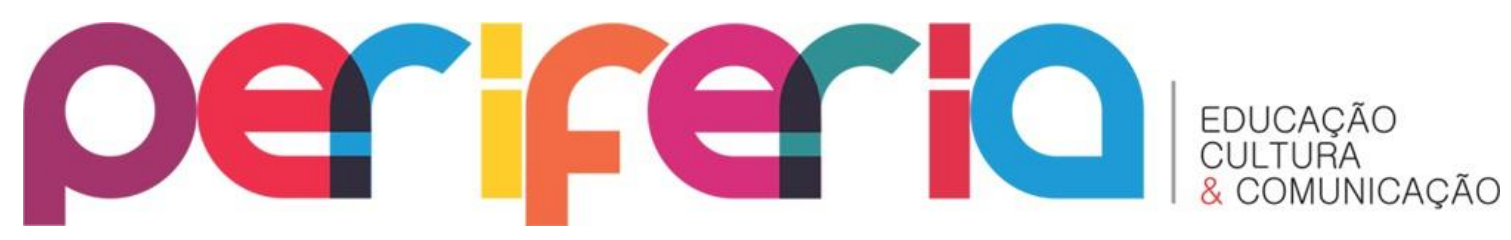

É importante ainda salientar que ao longo do processo histórico a escola foi depurando-se, complexificando-se, alargando-se, como afirma Saviani (2007), a ponto de ser considerada um modelo legítimo de educação para as demais formas. Embora possamos notar algumas continuidades, assim também como rupturas no desenvolvimento desta instituição, a escola.

É necessário conhecermos a história das instituições escolares, mas devemos estar atentos aos aspectos básicos que as constituem na sua materialidade, sua inserção social e seu público-alvo para compor o quadro da história da educação.

\section{ENTRE O PRIVADO E O PÚBLICO: O CASO DO PATRONATO SÃO BENTO}

O Patronato São Bento desde seu nascimento estabeleceu uma relação com as esferas públicas de âmbito municipal, estadual e federal dada a sua própria natureza, ou seja, instituição privada de caráter filantrópico com financiamento público. Por outro lado, por se constituir lugar de abrigo para os meninos pobres ou de comportamento considerado desviante, manteve relação direta com o judiciário. Nos momentos de fuga ou de delito maior a polícia também poderia ser acionada. 0 caráter filantrópico e caridoso atraiu o investimento de comerciantes e de personalidades importantes da cidade. Consequentemente por se caracterizar como instituição regida pela Igreja Católica favoreceu a presença frequente da imprensa local e de políticos fluminenses interessados na promoção pessoal.

A mesma não se apresentou diferente das demais instituições similares no período. Surgiu no seio da sociedade civil, mas imbricada com a sociedade política até porque inúmeros de seus agentes atuavam na mesma. Assim, um ano após o surgimento da ABM, foi lançada a pedra angular no bairro de Jardim Primavera em Duque de Caxias com a presença do governador Miguel Couto ${ }^{10}$.

${ }^{10}$ Os passos do governador em Duque de Caxias. 30 ago. 1956. 


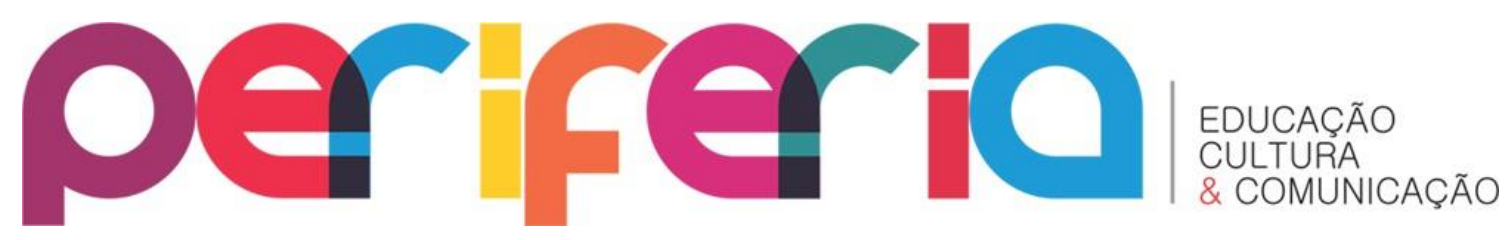

De acordo com o relatório das atividades do primeiro ano de funcionamento da instituição (1956), datado de 30 de janeiro de 1957, escrito por Dom Odilão OSB $^{11}$ na Cidade dos Meninos $^{12}$, relatava que no dia 2 de julho de 1956 o poder legislativo da cidade considerou a ABM como de utilidade pública e a isentou de impostos. Cabe o registro de que Dom Odilão atuava como capelão na Cidade dos Meninos, local de internamento de menores pela Fundação Abrigo Cristo Redentor, vinculada ao governo federal que compunha uma das glebas do Núcleo Colonial. Percebemos, como a instituição, embora fosse uma agência da sociedade civil de ordem particular e ligada a lgreja Católica, teve ligações com o poder público municipal, ao mesmo tempo em que foi considerada de utilidade pública e isenta de impostos numa sessão do poder legislativo municipal por conformar uma prática de controle social.

O pagamento de passagem de um menor encaminhado ao Abrigo Cristo Redentor $^{13}$ na Cidade dos Meninos, do guarda que o acompanhava, de outras passagens ao Instituto Profissional Getúlio Vargas na Cidade dos Meninos e o pagamento de impressos feitos pelo Instituto Profissional Getúlio Vargas demonstram uma ligação com a Fundação Abrigo Cristo Redentor que administrava os institutos que se localizavam na Cidade dos Meninos durante 1957. Diante do fato de que Dom Odilão atuava na Cidade dos Meninos como capelão, além de fazer parte da Legião Brasileira de Assistência local. Notamos uma tênue ligação entre esses espaços de internamento de meninos e meninas em situação de pobreza no mesmo território.

No mesmo relatório ${ }^{14}$, foi descrito que em julho do mesmo ano, o então prefeito e presidente da instituição, Francisco Correa desapropriou um terreno para que fosse erguido um prédio para abrigar os meninos em sistema de internato. Evidenciamos outro agente da sociedade política que atuou na

\footnotetext{
11 OSB - Ordem de São Bento. Nos documentos em que são assinados pelo padre ou fazem referência ao mesmo, sempre são acompanhados dessa sigla. A partir desse parágrafo não utilizaremos a sigla quando remetermos a ele.

12 Relatório de 1956, PSB 084.1, caixa 003.

${ }^{13}$ Relatório de 1957, PSB 083.1- 083.3, caixa 003.

${ }^{14}$ Relatório de 1956, PSB 084.1, caixa 003.
} 


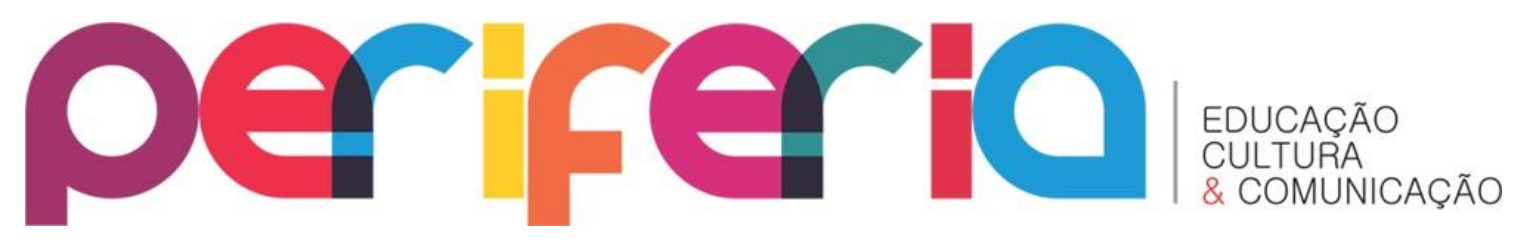

instituição por ser o prefeito "membro nato" da instituição na função de presidente. Francisco Correa assumiu como terceiro prefeito eleito da cidade de 31 de janeiro de 1955 a 15 de janeiro de 1959, concomitante ao período de institucionalização da ABM. Cabe ressaltar que desde que a cidade foi emancipada em 1943, seus dirigentes foram interventores estaduais até 1946.

O vereador Eri Teixeira, presidente da Câmara Municipal no ano de 1956, apareceu como alguém que articulava a campanha de cartões ${ }^{15}$ com o objetivo de arrecadar dinheiro da sociedade civil, além de exercer funções na ABM e corroborar na obtenção de verbas públicas municipais para a instituição.

A partir de 27 de outubro de 1956, Dr Gastão Glicério de Gouveia Reis contribuiu com a primeira $\operatorname{cota}^{16}$, uma cota significativa e constante com uma diferença dos demais contribuintes por serem intituladas como cotas. 0 mesmo foi interventor estadual na cidade de 25 de março de 1946 a 18 de outubro de 1946 e, posteriormente, prefeito eleito de 28 de setembro de 1947 a 31 de janeiro de 1951, pelo Partido Social Democrático (PSD). Essa é mais uma marca de personalidades públicas ligadas à política da cidade e do seu envolvimento com a $A B M$.

Até aqui percebemos a marcante intervenção e atuação de agentes da sociedade política municipal e consequentemente, o investimento de dinheiro público municipal. O relatório de $1956^{17}$ foi encerrado com a informação de que a instituição tinha dinheiro em caixa para comprar o terreno para construção do internato por terem recebido da Prefeitura Municipal Cr\$ $800.000,00$ proveniente do selo de diversões ${ }^{18}$.

Após o acordo feito na Câmara dos vereadores com o prefeito ${ }^{19}$, elaborou-se a deliberação 478, de 23 de agosto de 1957, para que fossem

\footnotetext{
${ }^{15}$ Livro Caixa, PSB 064.01 ao PSB 064.43, caixa 001.

${ }^{16}$ Livro Caixa, PSB 064.01 ao PSB 064.43, caixa 001.

${ }^{17}$ Relatório de 1956, PSB 084.2, da caixa 003.

${ }^{18}$ Esse selo correspondia a arrecadação de um imposto municipal sobre os estabelecimentos de diversão.

${ }^{19}$ Relatório de 1957, PSB 083.1- 083.3, caixa 003.
} 


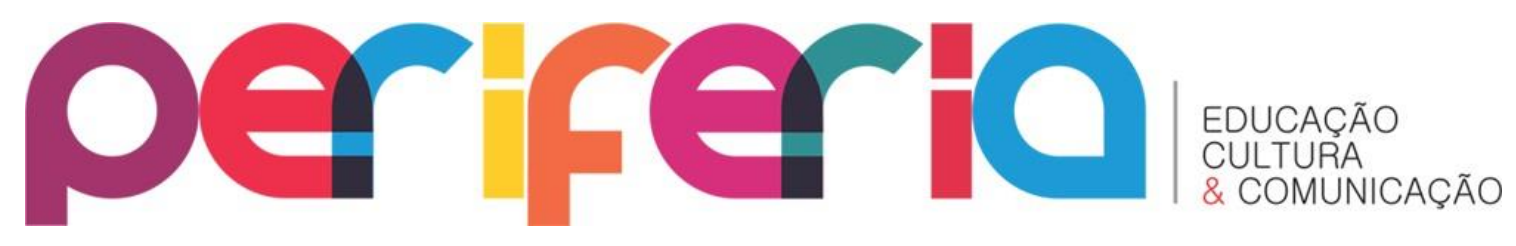

vendidos diretamente pela $A B M$ e pelo Ginásio Ana Maria Gomes que resolveu a questão do selo, entrando mensalmente para a instituição a partir dessa deliberação. Anteriormente, o dinheiro era apenas depositado pela prefeitura. A partir dessa deliberação, os selos puderam ser vendidos e através dos representantes legais do Ginásio Ana Maria Gomes, o dinheiro pode ser utilizado pela ABM.

Em 1958, a instituição continuava pagando ao tesoureiro da Prefeitura Municipal de Duque de Caxias (PMDC) pela venda dos selos de Diversões Públicas ${ }^{20}$, ou seja, continuavam recebendo essa forma de subvenção da PMDC. Em 1959, a PMDC21 deixou de pagar a cota dos selos de diversões públicas. A PMDC ainda tinha uma dívida com a instituição de dois milhões de cruzeiros e que não tinha possibilidade de ser quitada. A negação do recebimento dos selos por parte da PMDC, por ser uma inserção financeira significativa, dificultou a sua manutenção no começo do internato.

A atuação dos agentes na gestão da $A B M$ contribuiu para uma relação próxima da administração pública, como também na construção de caminhos para obtenção de subvenções de diferentes setores públicos: municipais, estaduais e federais.

No que diz respeito às verbas públicas concedidas pelo setor estadual, citamos a atuação do deputado Sá Rêgo ${ }^{22}$ na obtenção do valor de $\mathrm{Cr} \$$ $400.000,00$. E as verbas federais ${ }^{23}$ conseguidas por diferentes deputados no valor de $\mathrm{Cr} \$ 150.000,00$. Essas subvenções contribuíram para a manutenção da instituição ao longo de sua atuação, apesar de não apresentarem regularidade.

Além da obtenção de verbas públicas, foi instituída uma Campanha financeira ${ }^{24}$ junto à sociedade civil que atingiu o valor de $\mathrm{Cr} \$ 200.000,00$ que, segundo o relatório de 1956, gasto nas questões cotidianas. Desse valor

\footnotetext{
${ }^{20}$ Livro-caixa, PSB 064.120 - 064.182, caixa 001.

${ }^{21}$ Relatório de 1959, PSB 095.1, caixa 003.

22 SÁ REGO CONSEGUIU Cr\$ 900 MIL PARA OBRAS ASSISTENCIAIS NO MUNICÍPIO. 2 e 3 DEZ 1956.

${ }^{23}$ Relatório de 1956, PSB 084.2, da caixa 003.

${ }^{24}$ Relatório de 1956, PSB 084.2, da caixa 003.
} 


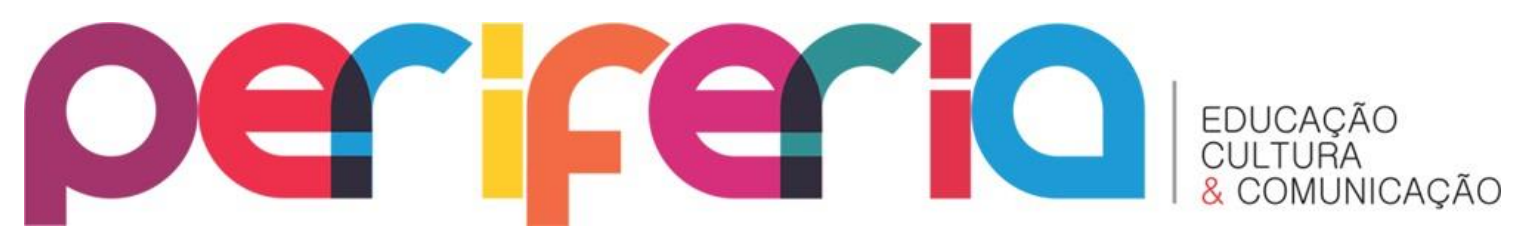

arrecadado, restou $\mathrm{Cr} \$ 50.000,00$. Foi relatado, ainda, nesse documento que a mesma conseguiu a confiança da sociedade caxiense pela prestação de contas mensal feita pelo tesoureiro que eram publicados pelo jornal local, a Folha da Cidade. Esse relato comprova a ingestão de dinheiro público e privado, provenientes de diferentes agentes da cidade. A atuação do bispo diocesano Dom Manoel Pedro, a partir de 29 de abril do ano corrente, foi mencionada pelo lançamento de uma “intensa" campanha financeira em que participaram “instituições públicas, privadas e pessoas de todas as idades e classes sociais $^{25}$ ". Referente a “intensa" campanha financeira ${ }^{26}$, percebemos que a partir de junho $d^{\circ}$ mesmo ano, foram feitas doações em dinheiro por: festa realizada no Núcleo Colonial São Bento, ação cinematográfica, campanha de cartões (da Escola São Bento, do Colégio Santo Antônio e Escolas Municipais), Desfile Infantil realizado na Associação Comercial, show artístico no Cine Clube Campos Elíseos, festival do circo Chabri, rifa, União Manufatora de Tecidos, Banco Itajubá S. A., indústria Rei H Weker, mercado Serve Bem, exploração de lenha da própria fazenda São Bento, Metalúrgica Hoffer S. A., Pedreira da Capela, Indústria de Bebidas Alves Ramos, entre outros. Esses aspectos marcaram o envolvimento de diferentes setores, na sua maioria, de agentes da sociedade civil na manutenção das atividades da ABM que começava a se instituir na cidade. A partir do mês de setembro de 1956 e de acordo com o documento citado anteriormente, apareceram agentes que contribuíam mensalmente para com a instituição, constatamos a cada mês, uma ampliação do quantitativo desses agentes. Dentre esses contribuintes, o próprio Dom Odilão, sua família e o bispo D Manoel Pedro da Cunha Cintra doaram também, assim como diferentes agentes da sociedade civil e da sociedade política, como vereadores, entre outros.

Entre janeiro e dezembro de $1957^{27}$, percebemos a permanência dos contribuintes mensais intitulada como campanha financeira também, a

\footnotetext{
${ }^{25}$ Relatório de 1956, PSB 084.1, caixa 003.

${ }^{26}$ Livro Caixa, PSB 064.01 ao PSB 064.43, caixa 001.

${ }^{27}$ Livro-caixa, PSB 064.44 - 064.121, caixa 001.
} 


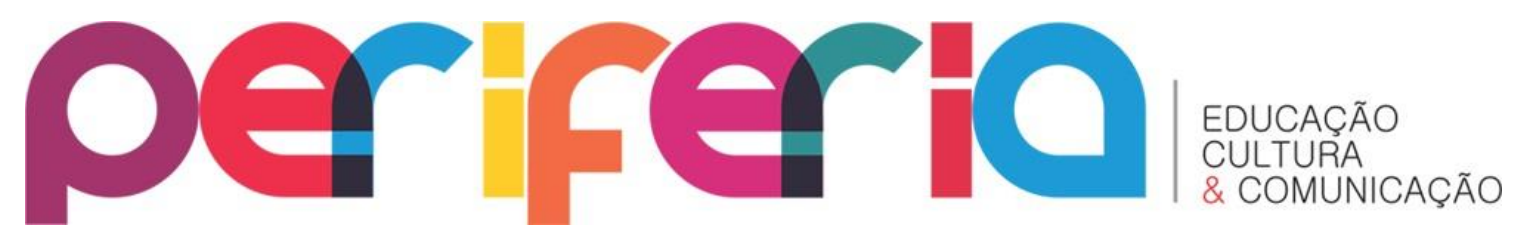

exploração de lenha, Banco hipotecário e agrícola do estado de Minas Gerais S. A., Casa São João Ltda, Casa Pinto, show, Pedreira da capela Ltda., indústria de Bebidas Alves Ramos Ltda., Metalúrgica Hoffer S/A, Casa da Banha Ltda., Casa Leque, Cantina Romana, Casa São João Ltda., Casa Pinto, Supermercado Serve Bem, Lojas Sud-Lux S/A, Colégio Santo Antônio, recebido por papel coletado, Casa Marconi, Drogaria Americanas Ltda., recebido da irmandade $\mathrm{N}$ Sra do Pilar por serviços prestados por um funcionário, entre outros. Dom Odilão, sua família, Dom Manoel Pedro Cintra, o vereador Eri Teixeira e as cotas de donativo do Dr Gastão Reis se repetem. Recebeu, ainda, do governo do Estado um auxílio financeiro concedido pelo serviço de Loteria do estado do Rio de Janeiro.

De janeiro a dezembro de $1958^{28}$, a doação feita por particulares permaneceu, assim como o pagamento dos Selos de Diversões Públicas. A partir do mês de maio, a Casa São José passou a receber contribuição mensal dos garotos assistidos. Em todos os meses do ano de 195929, continuou recebendo a contribuição mensal dos garotos. A ABM recebeu nesse mesmo período doação em dinheiro da União Democrática Nacional de Duque de Caxias (UDN). A partir de maio, houve registro de recebimento de subvenções federais vindo da Legião Brasileira de Assistência (LBA) também. Entre os anos de 1956 e 1959, percebemos a inserção gradativa de verbas públicas na instituição e, paralelamente, a contribuição de particulares que foi diminuindo após o início do internamento dos menores. Esse aspecto caracteriza, novamente, a $A B M$ como uma instituição privada que recebia subvenções públicas.

A partir da análise dos documentos de $1956^{30}$, percebemos uma tentativa de estabelecimento da instituição. Principalmente, na legalização de documentos para que pudessem receber as subvenções. Apesar de não

\footnotetext{
${ }^{28}$ Livro-caixa, PSB 064.120 - 064.182, caixa 001.

${ }^{29}$ Livro-caixa, PSB 064.183 - 064.263, caixa 001.

${ }^{30}$ Relatório de 1956, PSB 084.1, caixa 003.
} 


\section{periferio}

terem o espaço para o internamento, a instituição já fazia atividades assistenciais através do atendimento de 431 meninos trabalhadores.

No relatório ${ }^{31}$ do ano constavam as dificuldades enfrentadas na construção do Patronato, algumas providências importantes para regularização da arrecadação das verbas do selo de diversões públicas que estavam depositadas na Prefeitura desde setembro de 1956. Quanto ao terreno doado pela prefeitura, foi relatado que não houve acordo com o dono do terreno em relação à venda. Entretanto, foi doado um terreno no Parque Beira Mar para construção do espaço de internamento que seria Instituto Profissional São José, essa é a primeira denominação. Ainda em 1957, foi feito um levantamento topográfico do Núcleo Colonial São Bento ${ }^{32}$, essa é uma marca do vínculo com o governo federal. O levantamento topográfico da região da Fazenda São Bento caracterizou a dificuldade em conseguir um espaço para o internato.

As verbas arrecadadas, públicas ou privadas, eram utilizadas para as atividades que relacionaremos a seguir. 0 trabalho que vinha sendo desempenhado no gabinete do prefeito, em 1956, continuou na sede denominada de Casa São José33. Em 1957, pagavam pelo aluguel da Casa São José para o atendimento dos meninos que consistia em reuniões semanais e posteriormente, adaptaram o espaço para que pudessem acontecer aulas noturnas para os meninos e meninas, com duas professoras, uma da prefeitura e outra paga pela $A B M$, assim como o pagamento de uma assistente social. Foram atendidos 521 meninos (404 meninos e 117 meninas). No ano seguinte ${ }^{34}$, pagavam a professora Martha Rossi para que continuasse o trabalho na Casa São José e continuaram pagando pelo serviço da professora Martha Rossi ${ }^{35}$ em 1959. Notamos que apenas no ano de 1957, houve um convênio com a prefeitura para a cessão da professora, mas nos anos

\footnotetext{
${ }^{31}$ Relatório de 1957, PSB 083.1- 083.3, caixa 003.

32 Relatório de 1957, PSB 083.1- 083.3, caixa 003.

${ }^{33}$ Relatório de 1957, PSB 083.1- 083.3, caixa 003.

${ }^{34}$ Livro-caixa, PSB 064.120 - 064.182, caixa 001.

${ }^{35}$ Livro-caixa, PSB 064.183 - 064.263, caixa 001.
} 


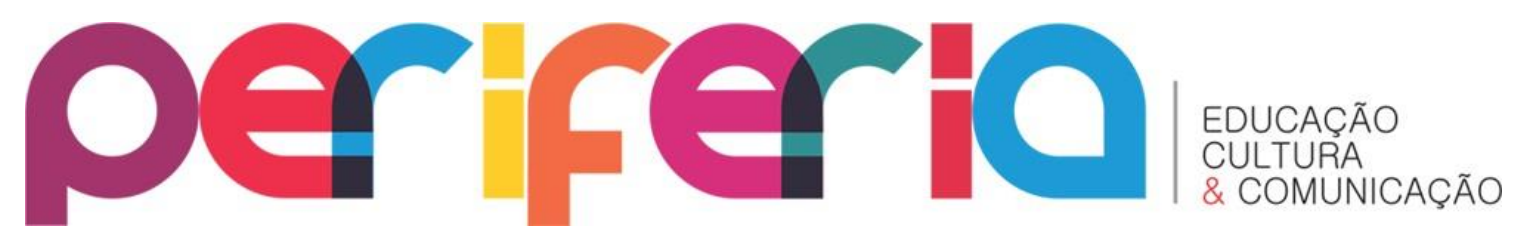

seguintes, esse convênio não continuou. Embora, a dificuldade dos meninos trabalhadores em estudar fosse uma realidade.

Ainda no relatório de $1957^{36}$ apresentava, 66 engraxates que trabalhavam nas ruas com féria média de $\mathrm{Cr} \$ 70,00$, com ponto fixo e um chefe. $\mathrm{O}$ dos baleiros foi de $\mathrm{Cr} \$ 40,00$, além da aquisição da mercadoria ter passado a ser feita em casa credenciada pela $A B M$. No ano seguinte, confeccionavam uniformes para os meninos ${ }^{37}$ com o intuito de que fossem identificados nas ruas da cidade, o que facilitava o recolhimento daqueles que não estivessem identificados. A confecção de uniformes ${ }^{38}$ permaneceu no decorrer de 1959. Embora, não tenhamos a relação dos espaços comerciais onde esses meninos compravam as suas mercadorias para venda. É importante evidenciar o controle exercido sobre esses meninos e meninas através de uma interferência direta nas suas atividades desde a compra dos materiais vendidos como nas suas roupas. Dentre os meninos atendidos, alguns receberam carteiras de trabalho ${ }^{39}$ e outros conseguiram o trabalho em fábricas. No ano de 1959, alguns dos meninos trabalharam no reparo e na conservação do mosteiro da Fazenda São Bento ${ }^{40}$. A inserção no trabalho era uma tarefa constante na instituição.

Nesse início, diante do fato da delegacia local não ter um espaço para que os menores infratores não ficassem presos com os adultos. A $A B M$ construiu um anexo para que os menores detidos ficassem separados dos presos adultos. Em 1958, continuou a construção de um compartimento anexo ${ }^{41}$ ao distrito policial para recolhimento de menores detidos. Há referência também de refeições que foram oferecidas aos menores detidos, assim como a passagem para condução de menores para internação no Serviço de Assistência ao Menor (SAM) ligado ao Ministério da Justiça com uma

\footnotetext{
${ }^{36}$ Relatório de 1957, PSB 083.1- 083.3, caixa 003.

${ }^{37}$ Livro-caixa, PSB 064.120 - 064.182, caixa 001.

${ }^{38}$ Livro-caixa, PSB 064.183 - 064.263, caixa 001.

${ }^{39}$ Relatório de 1957, PSB 083.1- 083.3, caixa 003.

${ }^{40}$ Livro-caixa, PSB 064.183 - 064.263, caixa 001.

${ }^{41}$ Livro-caixa, PSB 064.120 - 064.182, caixa 001.
} 


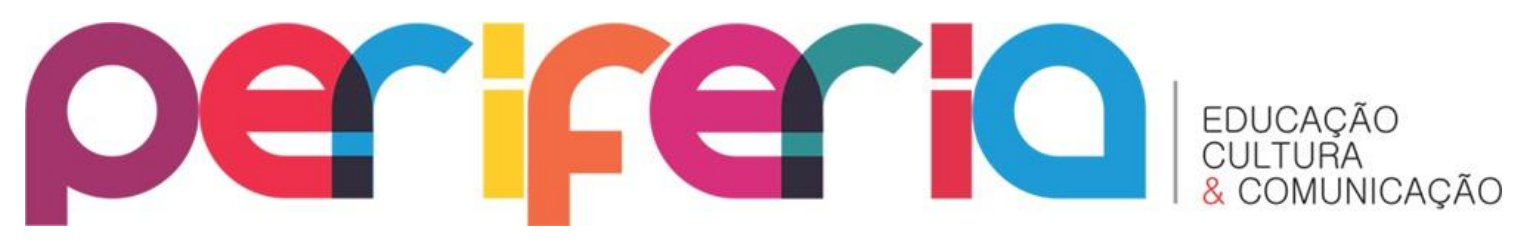

proposta correcional. No ano seguinte, continuaram o oferecimento das refeições aos menores detidos ${ }^{42}$. Essa atuação junto aos menores infratores foi algo que permaneceu na atuação da instituição.

A partir de junho de $1959^{43}$ houve registro de compra de alimentos em grande quantidade, de tamanco, de pijamas, de consulta médica dos alunos, de móveis, de confecção de calças curtas, de vídeo game, de gás de cozinha, de conserto de geladeira, de material de limpeza, de compra de frutas, de trabalho de pedreiro e de carpinteiro. A LBA forneceu utensílios e a partir de junho, iniciou-se o trabalho de internação dos meninos no Patronato São Bento. Como não foi possível a construção de uma sede própria, o espaço de internamento teve que funcionar na Fazenda São Bento. Assim, o espaço de internamento passou a ser denominado Instituto Profissional São Bento.

Num relatório sobre as atividades da ABM no ano de 1959, enviado ao bispo da diocese de Petrópolis, D Odilão relatou que finalmente, em julho do referido ano, conseguiriam concretizar o trabalho que a $A B M$ desejava o de construir um Patronato para o acolhimento dos meninos "após quatro anos de trabalho incessantes (...) a fundação e manutenção de um estabelecimento de internação de menores de acordo com o estatuto da $A B M^{44 "}$. O relator ainda assinalou sobre o fato dos "Aliados aos poderes públicos para amparar os meninos desvalidos da sociedade", dentre esses agentes, há referência ao que ocupava o poder executivo municipal (prefeito), o legislativo municipal (alguns vereadores) e o judiciário como os Juízes Ary Fontenelle e Hélio Albernaz. Ele ainda mencionou a Associação Comercial e a imprensa local, colaboradores nas atividades da ABM.

No ano da institucionalização do Patronato, houve a eleição da gestão do novo triênio da ABM. Foram indicados $\operatorname{Dr}$ Jorge Armênio para a função de presidente, Dr. Gastão Reis para a função de vice-presidente, José Maia para tesoureiro, Joaquim Vieira Jr como segundo tesoureiro. 0 expediente que era

\footnotetext{
42 Livro-caixa, PSB 064.183 - 064.263, caixa 001.

${ }^{43}$ Livro-caixa, PSB 064.183 - 064.263, caixa 001.

${ }^{44}$ Relatório de 1959, PSB 095.1, caixa 003.
} 


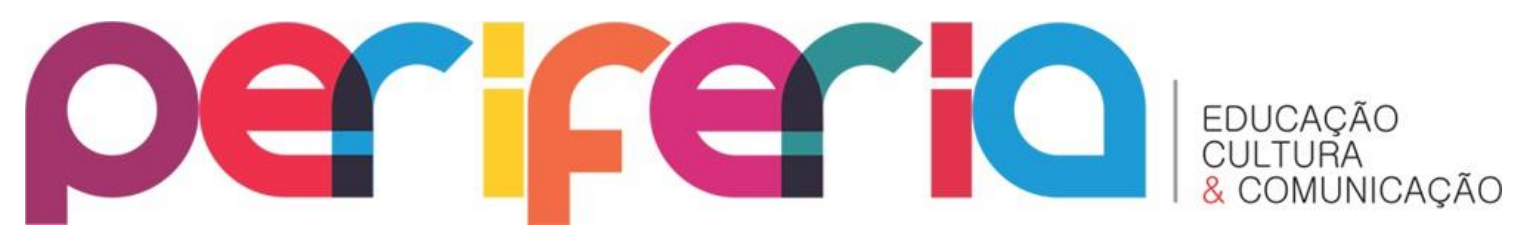

na Casa São José passou a ser feito na Fazenda, consequentemente a casa foi fechada. Mas, continuou prestando serviços aos meninos que trabalhavam como engraxates. Apesar de o prefeito ter feito a tentativa de impedir o trabalho dos engraxates nas ruas, o juiz Hélio Albernaz não permitiu. Assim, continuavam com 40 engraxates registrados. Durante as enchentes que assolaram a cidade no ano de 1958, a ABM assistiu os flagelados e a LBA custeou 25 alunos no internato ${ }^{45}$. Dessa forma, o espaço de internamento começou a funcionar.

\section{CONSIDERAÇÕES FINAIS}

0 artigo trouxe a proposição de fazer algumas pontuações quanto algumas marcas da institucionalização do Patronato São Bento. Principalmente, sobre o investimento financeiro e a inserção de pessoas públicas no trabalho da instituição que faz com que embora fosse uma instituição privada, recebia verbas públicas.

Foi possível identificar a instituição escolar que é o patronato São Bento e identificar algumas de suas contribuições para este campo da história da educação no território da Baixada Fluminense.

Esse projeto atendeu aos interesses de um determinado grupo que esteve em sintonia com os interesses estaduais e nacionais. Essa pesquisa sobre o Patronato São Bento contribui para a renovação temática do campo historiográfico, assim como do entendimento do assistencialismo no município de Duque de Caxias marcado pela intervenção da Igreja Católica e seus agentes, além do controle social de caráter moralizante tanto dos meninos quanto das próprias famílias.

Esse assistencialismo na cidade esteve ligado, ainda, ao judiciário desde sua constituição inicial através da injeção de diferentes verbas públicas numa instituição privada (ABM). Essa investigação contribui para descortinar

${ }^{45}$ Relatório de 1959, PSB 095.2, caixa 003. 


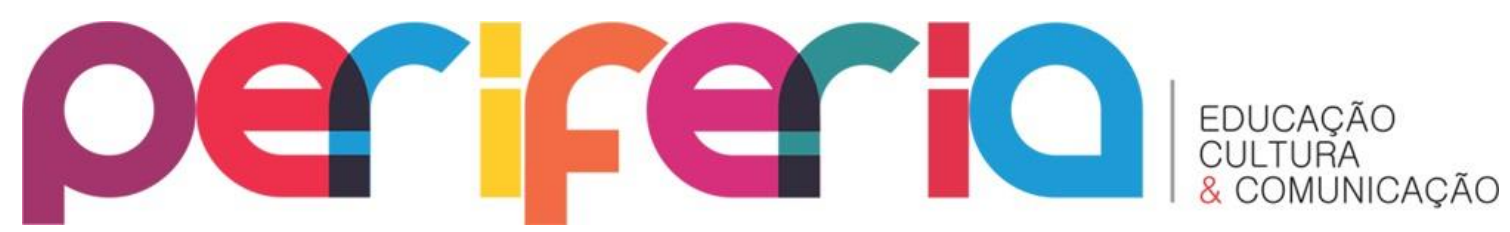

novos universos documentais e de análise e, consequentemente contribuir para a renovação da temática do campo historiográfico.

O entendimento da relação da Sociedade Civil com a Sociedade Política que se articula no e pelo Estado restrito a partir da análise inicial de seus agentes e suas práticas desvela o direcionamento de verbas das esferas públicas de âmbito municipal, estadual e federal. Além desse caráter filantrópico no tratamento das questões para uma determinada infância apresentar a atuação de diferentes agentes, principalmente os vinculados ao

Ministério da Justiça. Auxiliam assim para a compreensão da história da infância.

\section{REFERÊNCIAS BIBLIOGRÁFICAS}

DIAS, Amália. Entre laranjas e letras: processos de escolarização no distritosede de Nova Iguaçu (1916-1950). Rio de Janeiro: Quartet; FAPERJ, 2014.

MENDONÇA, Sônia Regina de. Estado e educação rural no Brasil: alguns escritos. Niterói, Rio de Janeiro: Vício de Leitura, FAPERJ, 2007.

. Estado, educação rural e influência norte-americana no Brasil (19301961). Niterói: Editora da UFF, 2010.

OS PASSOS DO GOVERNADOR EM DUQUE DE CAXIAS. Folha da cidade. Duque de Caxias, 30 de agosto de 1956, ano III, n. 10, p. 05, 1956.

SÁ REGO CONSEGUIU CR\$ 900 MIL PARA OBRAS ASSISTENCIAIS NO MUNICÍPIO. Folha da cidade. Duque de Caxias, 2 e 3 de dezembro de 1956, ano III, n. 23, p. 06, 1956.

SAVIANI, Dermeval. Instituições escolares no Brasil: conceito e reconstrução histórica. In: NASCIMENTO, Maria Isabel Moura et al (orgs.). Instituições escolares no Brasil: conceito e reconstrução histórica. Autores Associados: Histedbr; Sorocaba, SP: UNISO; Ponta Grossa, PR: UEPG, 2007. 